\title{
Intra-abdominal hypertension is an independent cause of acute renal failure after orthotopic liver transplantation
}

\author{
SHU Ming $(\varangle)^{1}$, PhD, PENG Chenghong ${ }^{2}$, PhD, CHEN Hao ${ }^{2}$, PhD, SHEN Boyong², MD, ZHOU Guangwen², PhD, \\ SHEN Chuan'², MS, LI Hongwei ${ }^{2}$, PhD \\ 1 Department of General Surgery, Ningbo No. 2 Hospital, Ningbo 315010, China \\ 2 Institute of Digestive Surgery, Ruijin Hospital, Shanghai Jiao Tong University, Shanghai 200025, China
}

(C) Higher Education Press and Springer-Verlag 2007

\begin{abstract}
An independent association between acute renal failure (ARF) and intra-abdominal hypertension (IAH) after liver transplantation has not been established previously. The aim of this retrospective study was to understand the role of IAH as an independent risk factor for ARF in the early postoperative period. This study involved 62 subjects who underwent liver transplantation. Intra-abdominal pressure (IAP) was measured in the first three days after surgery by using the urinary bladder technique. An IAP of at least $20 \mathrm{mmHg}$ per day was defined as IAH. Clinical parameters between group IAH and group NO-IAH were compared in terms of the incidence of ARF, blood creatinine levels, blood urea nitrogen (BUN) levels, urine volume per hour and glomerular filtration gradient (GFG). Hemodynamic variations were recorded in the first three postoperative days between group ARF and group NO-ARF. The perioperative suspected risk factors of ARF were determined for statistical evaluation using correlation coefficients and logistic regression analysis. In group IAH, $45.8 \%$ patients developed ARF as against $7.9 \%$ in group NO-IAH; GFG was significantly lower at $0-72 \mathrm{~h}$ after surgery; and blood creatinine levels, BUN levels, urine volume per hour were significantly different at 24-72 h after surgery compared with group NO-IAH. The patients with ARF were not significantly different from those without ARF in terms of central venous pressure, pulmonary artery pressure and mean arterial pressure (MAP) in the first three postoperative days despite a significant increase in heart rate at 24-72h after operation. Postoperative IAH, intraoperative MAP and intraoperative blood transfusion volume of more than $15 \mathrm{U}$ were found to be independent risk factors for ARF. IAH impaired renal function and was an independent risk factor for ARF after liver transplantation. Routine
\end{abstract}

Translated from Chinese Journal of Organ Transplantation, 2006, 27(1): 22-25 [译自: 中华器官移植杂志]

E-mail: sm-680602@sohu.com measurement should be taken to monitor IAP every eight hours postoperatively.

Keywords liver transplantation; intra-abdominal hypertension; renal failure, acute

\section{Introduction}

Orthotopic liver transplantation (OLT) is burdened with acute renal failure (ARF), with an incidence ranging from $10 \%$ to $25 \%$, and a mortality rate that exceeds $50 \%$ when renal replacement therapy is required $[1,2]$; in this setting, even moderate renal dysfunction is significantly associated with shortened graft and recipient survival [3].

There are many specific characteristics of the liver transplant procedure. These include frequent intra-peritoneal hemorrhages (surgical or due to coagulopathy), bowel congestion due to portal hypertension and/or large-scale fluid administration and accumulation of massive ascitic fluid. All these factors put patients at risk for intra-abdominal hypertension (IAH) in the immediate postoperative period.

Although it has been known for more than a century that IAH is associated with renal impairment, few studies have reported on the adverse physiological effects of IAH on renal function after OLT $[4,5]$. To our knowledge, an independent association between ARF and IAH after OLT has not been established. The aim of this retrospective study was therefore to understand the role of IAH as an independent risk factor for ARF in patients who underwent OLT.

\section{Patients and methods}

This retrospective study involved all 62 subjects consecutively undergoing cadaveric OLT in Ruijin hospital from September 2003 to January 2005. All subjects signed an 
informed consent for study participation, which had been approved by the local Institutional Human Subjects Committee and Ruijin hospital Ethics Committee. The exclusion criteria included preoperative diagnosis of renal dysfunction, the onset of infection, respiratory complications and graft function problems based on standard criteria [6-8]. Fortyeight men and 14 women were included in this research, with a mean age of 48.03 years. Twenty-six cases suffered from HBV hepatic cirrhosis, 14 from primary carcinoma of the liver, 14 from acute severe hepatitis, six from biliary cirrhosis and two from alcoholic cirrhosis. Donors had identical blood types with that of recipients. Classic OLT was performed in 17 cases, piggyback OLT in 43 cases, and split liver transplantation in two cases. All of the OLTs done without extracorporeal venovenous bypass were performed by the same group of surgeons.

The immunosuppressive protocol included tacrolimus (maintained at a trough blood concentration of 8-12 ng/mL) and methylprednisolone (1000 mg intraoperatively, subsequently reduced by $50 \%$ every day until reaching a prednisolone dose of $20 \mathrm{mg} / \mathrm{d}$ ). Immunosuppression was completed after intravenous administration of basiliximab $(20 \mathrm{mg})$ on the first and fourth postoperative day. There were no differences in preventive therapeutical protocols for bacterial, virus and fungal infections.

IAP was measured by using the urinary bladder technique modified by Kron et al. [9], after the patients had been placed in a supine position and disconnected from the ventilator. The symphysis pubis was used as reference line. IAP was measured twice before OLT was done, and at least every eight hours in the first three postoperative days.

IAH was defined as a mean intra-abdominal pressure (IAP) per day of equal to or more than $20 \mathrm{mmHg}$ in the first three days after OLT. The 62 patients were divided into two groups: those with IAH (group IAH) and those without IAH (group NO-IAH). Time was recorded at the emergence of IAH. Hepatic function in both groups was assessed as activated partial thromboplastin time ratio, prothrombin time, alanine aminotransferase, aspartate aminotransferase, blood total bilirubin and connect bilirubin on the fourth day after OLT.

According to Sugrue's definition [6], ARF was identified as a postoperative blood creatinine $(\mathrm{Cr})$ level of more than $130 \mu \mathrm{mol} / \mathrm{L}$ or an increase in blood $\mathrm{Cr}$ of greater than $100 \mu \mathrm{mol} / \mathrm{L}$ within 72 hours after surgery. The 62 patients were thus accordingly divided into two groups: group ARF and group NO-ARF. Hemodynamic variables [heart rate (HR), central venous pressure (CVP), pulmonary artery pressure (PAP) and mean arterial pressure (MAP)] of both groups were recorded in the first three postoperative days.

The incidence of ARF and cases that required continuous renal replacement in group IAH and group NO-IAH were documented. Blood creatinine levels, blood urea nitrogen (BUN) levels and urine volume per hour were recorded in the first three postoperative days. MAP was measured at the same time points when postoperative IAP was recorded. The glomerular filtration gradient (GFG) was calculated according to the formula: GFG $=\mathrm{MAP}-(2 \times \mathrm{IAP})$ [10].

We analyzed the perioperative suspected risk factors of ARF such as age, preoperative hypertension, intraoperative MAP, unit of intraoperative blood transfusion, operative pattern (classic/piggyback/split transplantation), anhepatic time as well as postoperative sepsis, respiratory failure, initial poor graft function (based on the Nanashima's suggestion [11]), relaparotomy (for abdominal hematoma cleaning or hemostasia), mean administration dose of diuretics and postoperative IAH in the first three days. ARF and IAH were considered to be potentially related with each other if they occurred within 48 hours postoperatively.

All data were analyzed with SPSS 11.0 software (SPSS, Inc., Chicago, USA). The results were presented as $\bar{x} \pm s$ or percent rate. The student's $t$ test was used for unpaired numerical data analysis, and either the Pearson $x^{2}$ test or Fisher's exact test was used for nominal data. Correlation coefficients were adopted to determine the correlation between continuous variables. Logistic regression and forward stepwise regression were used to evaluate the independent risk factors for ARF. Statistical significance was set at $P<0.05$.

\section{Results}

Of the 62 patients, none of the patients' preoperative IAP exceeded $6 \mathrm{mmHg}$. Twenty-four (38.7\%) had IAH and $38(61.3 \%)$ did not show a high IAP after operation. Of the 24 patients with IAH, 19 (79.2\%) developed IAH at 0-24 h postoperatively, with the other five $(20.8 \%)$ at $24-48 \mathrm{~h}$ postoperatively. In both groups, the values lasted at least until the third day after surgery.

Eleven (45.8\%) patients in group IAH developed ARF, four of whom demonstrated oliguria or anuria, against three (7.9\%) ARF cases in group NO-IAH $\left(x^{2}=12.11, P=0.01\right)$. Continuous renal replacement therapy was required in three members of group IAH but none for group NO-IAH $(P=0.054)$. Hospital mortality rates were $12.5 \%$ and $5.3 \%$ in group IAH and group NO-IAH, respectively $(P=0.366)$. Statistical differences between group IAH and group NO-IAH were noted in blood Cr levels, BUN levels and urine volume per hour at $24-48 \mathrm{~h}$ and at $48-72 \mathrm{~h}(P<0.01$ or $P<0.05$, Table 1 ) postoperatively. GFG in group IAH was significantly lower than that in group NO-IAH in the first three days postoperatively $(P<0.01$, Table 1$)$, revealing that renal function was impaired quickly and continuously in IAH.

There were no significant differences in activated partial thromboplastin time ratio, prothrombin time, alanine aminotransferase, aspartate aminotransferase and blood total bilirubin levels between the two groups, but blood connect bilirubin levels of patients with IAH were significantly higher than those with a normal IAP on the fourth day after OLT $(P<0.05$, Fig. 1$)$. 
Table 1 Comparison of the IAP and renal function between group IAH and group NO-IAH in the first three days after OLT

\begin{tabular}{|c|c|c|c|c|c|c|}
\hline $\begin{array}{l}\text { Postoperative IAP and } \\
\text { renal function }\end{array}$ & \multicolumn{2}{|c|}{$0-24 \mathrm{~h}$} & \multicolumn{2}{|c|}{$24-48 \mathrm{~h}$} & \multicolumn{2}{|c|}{$48-72 \mathrm{~h}$} \\
\hline IAP (mmHg) & $24.35 \pm 6.06^{a)}$ & $14.63 \pm 3.51$ & $26.25 \pm 5.99^{a)}$ & $14.21 \pm 3.25$ & $23.22 \pm 4.59^{\mathrm{a})}$ & $13.16 \pm 4.37$ \\
\hline $\mathrm{BUN}(\mathrm{mmol} / \mathrm{L})$ & $12.19 \pm 6.44$ & $9.67 \pm 5.04$ & $13.63 \pm 8.99^{a)}$ & $7.91 \pm 4.47$ & $13.63 \pm 9.29^{b)}$ & $10.09 \pm 4.50$ \\
\hline Urine volume/h $(\mathrm{mL} / \mathrm{h})$ & $96.68 \pm 51.87$ & $106.15 \pm 41.15$ & $74.49 \pm 56.64^{\mathrm{a})}$ & $114.0 \pm 39.21$ & $77.13 \pm 51.39^{\mathrm{a})}$ & $115.0 \pm 36.88$ \\
\hline GFG (mmHg) & $30.14 \pm 16.52^{\mathrm{a})}$ & $52.9 \pm 11.66$ & $29.61 \pm 17.42^{\mathrm{a})}$ & $58.36 \pm 12.48$ & $35.28 \pm 18.60^{\mathrm{a})}$ & $61.32 \pm 11.71$ \\
\hline
\end{tabular}

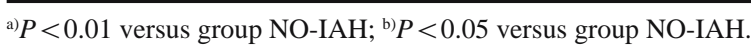

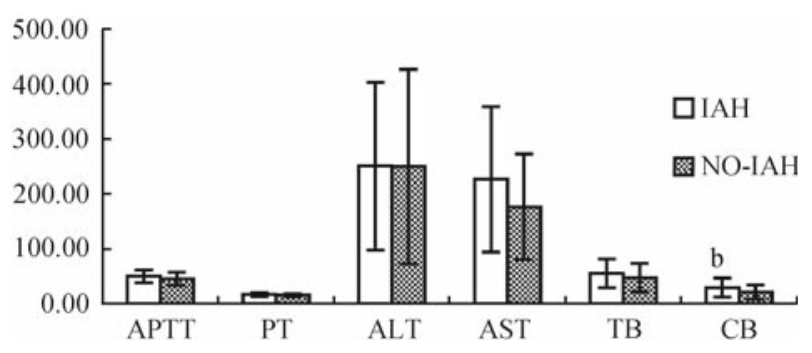

Fig. 1 Comparsion of liver function between group IAH and group NO-IAH on the fourth day after OLT. $P<0.05$. APTT: activated partial thromboplastin time ratio; PT: prothrombin time; ALT: alanine aminotransferase; AST: aspartate aminotransferase; TB: total bilirubin; CB: connect bilirubin

Of the 62 patients, 14 (22.6\%) patients developed ARF, and 48 subjects did not develop ARF (NO-ARF). The patients with ARF were not significantly different from those without
ARF in terms of CVP, PAP and MAP in the first three days after OLT, despite a significant increase in HRs at $24-72 \mathrm{~h}$ $(P<0.01$ or $P<0.05$, Table 2$)$.

The prevalence of risk factors for ARF is summarized in Table 3. Analysis of correlation coefficients showed that ARF was significantly correlated with factors such as age more than 60 years, intraoperative blood transfusion volume more than $15 \mathrm{U}$, intraoperative MAP, postoperative IAH, postoperative sepsis and postoperative respiratory failure in the first three days ( $P<0.01$ or $P<0.05$, Table 3 ). On the other hand, no significant correlation was found with the following factors: preoperative hypertension, anhepatic time, operative pattern, initial poor graft function, postoperative relaparotomy and mean administration dose of diuretics $(0-72 \mathrm{~h}$ postoperative).

Logistic regression analysis revealed that ARF was significantly and independently correlated with postoperative

Table 2 Analysis of hemodynamic variations between group ARF and group NO-ARF in the first three days after OLT

\begin{tabular}{|c|c|c|c|c|c|c|}
\hline Variables & \multicolumn{2}{|c|}{$0-24 \mathrm{~h}$} & \multicolumn{2}{|c|}{$24-48 \mathrm{~h}$} & \multicolumn{2}{|c|}{$48-72 \mathrm{~h}$} \\
\hline $\mathrm{HR} / \mathrm{min}$ & $109.71 \pm 18.57$ & $102.77 \pm 19.77$ & $109.64 \pm 22.00^{\mathrm{b}}$ & $96.38 \pm 15.37$ & $108.64 \pm 18.77^{\mathrm{a})}$ & $95.29 \pm 12.54$ \\
\hline PAP (mmHg) & $22.21 \pm 5.01$ & $20.27 \pm 4.67$ & $17.86 \pm 3.97$ & $17.63 \pm 4.90$ & $16.50 \pm 4.23$ & $17.19 \pm 4.80$ \\
\hline MAP (mmHg) & $79.30 \pm 12.43$ & $80.77 \pm 10.81$ & $82.86 \pm 10.27$ & $85.06 \pm 12.53$ & $81.37 \pm 13.83$ & $86.27 \pm 12.49$ \\
\hline
\end{tabular}

${ }^{\text {a) }} P<0.01$ versus group NO-ARF; b) $P<0.05$ versus group NO-ARF.

Table 3 Analysis of the prevalence of risk factors for ARF after OLT

\begin{tabular}{|c|c|c|c|c|c|}
\hline Risk factors assessed & $\operatorname{ARF}(n=14)$ & NO-ARF $(n=48)$ & $P$ & $\mathrm{RR}^{\mathrm{c})}$ & $95 \% \mathrm{CI}^{\mathrm{d})}$ \\
\hline Age (>60 y) (n\%) & $5(35.7 \%)^{b)}$ & $4(8.3 \%)$ & 0.01 & 6.11 & $1.36-27.32$ \\
\hline Preoperative hypertension (n\%) & $2(14.3 \%)$ & $5(10.4 \%)$ & 0.693 & 1.43 & $0.24-8.33$ \\
\hline Intraoperative MAP (mmHg) & $75.0 \pm 7.81^{\mathrm{b})}$ & $81.76 \pm 9.59$ & 0.019 & - & - \\
\hline $\begin{array}{l}\text { Intraoperative blood transfusion volume } \\
\text { more than } 15 \mathrm{U}(\mathrm{n} \%)\end{array}$ & $9(64.3 \%)^{\mathrm{a})}$ & $9(18.8 \%)$ & 0.001 & 7.80 & $2.10-28.95$ \\
\hline $\begin{array}{l}\text { Operative pattern: } \\
\text { classic/piggyback/split (n\%) }\end{array}$ & $\begin{array}{c}6 / 8 / 0 \\
(42.9 \% / 57.1 \% / 0 \%)\end{array}$ & $\begin{array}{c}11 / 35 / 2 \\
(22.9 \% / 72.9 \% / 4.2 \%)\end{array}$ & 0.115 & - & - \\
\hline Anhepatic time (min) & $45.79 \pm 7.50$ & $45.33 \pm 7.48$ & 0.843 & - & - \\
\hline Postoperative IAH (n\%) & $11(78.6 \%)^{\mathrm{a})}$ & $13(27.1 \%)$ & 0.0003 & 9.87 & $2.37-41.10$ \\
\hline Initial poor graft function ( $\mathrm{n} \%$ ) & $4(28.57 \%)$ & $8(12.9 \%)$ & 0.329 & 2.00 & $0.50-7.99$ \\
\hline Postoperative sepsis (n\%) & $4(28.6 \%)^{b)}$ & $4(8.3 \%)$ & 0.048 & 4.40 & $0.93-20.66$ \\
\hline Postoperative respiratory failure (n\%) & $7(50.0 \%)^{\mathrm{a})}$ & $5(10.4 \%)$ & 0.001 & 8.60 & $2.12-34.81$ \\
\hline Postoperative relaparotomy (n\%) & $3(21.4 \%)$ & $5(10.4 \%)$ & 0.287 & 2.34 & $0.48-11.35$ \\
\hline Diuretics (mg/d) & $31.42 \pm 12.92$ & $26.67 \pm 5.77$ & 0.052 & - & - \\
\hline
\end{tabular}

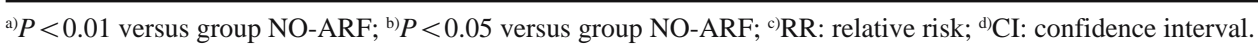


IAH, intraoperative MAP and intraoperative blood transfusion volume of more than $15 \mathrm{U}(P<0.05$, Table 4). Multivariate forward stepwise regression model showed identical outcomes: intraoperative MAP $(P=0.007)$, postoperative IAH $(P=0.012)$ and intraoperative blood transfusions of more than $15 \mathrm{U}(P=0.017)$ were the high-risk factors for ARF after OLT.

Table 4 Logistic regression analysis of independent risk factors for ARF

\begin{tabular}{lcccc}
\hline Variables & $\begin{array}{c}\text { Wald } \\
\text { statistic }\end{array}$ & $P$ & $\mathrm{OR}^{\mathrm{b})}$ & $95 \% \mathrm{CI}$ \\
\hline Age (>60 y) & 0.363 & 0.547 & 2.15 & $0.17-25.95$ \\
$\begin{array}{l}\text { Intraoperative blood transfusion } \\
\quad \text { volume of more than 15 U }\end{array}$ & $3.972^{\mathrm{a})}$ & 0.046 & 15.75 & $1.04-237.11$ \\
Intraoperative MAP & $5.046^{\mathrm{a})}$ & 0.025 & 1.15 & $1.01-1.30$ \\
Postoperative IAH & $5.809^{\mathrm{a})}$ & 0.016 & 18.36 & $1.72-195.80$ \\
Postoperative sepsis & 2.857 & 0.091 & 9.85 & $0.69-139.80$ \\
Postoperative relaparotomy & 1.191 & 0.275 & 0.19 & $0.01-3.73$ \\
Postoperative respiratory failure & 2.269 & 0.132 & 0.073 & $0.002-2.19$ \\
Diuretics & 1.444 & 0.229 & 0.93 & $0.83-1.04$ \\
\hline
\end{tabular}

a) $P<0.05$; ${ }^{\text {b) }} \mathrm{OR}$ : odds ratio.

\section{Discussion}

Since the abdominal cavity is a limited space considered as a single compartment, any variations in its content can influence abdominal cavity pressure [12]. These variations may result from any step in OLT intraoperatively or postoperatively as follows: (1) bleeding and/or hematoma developing from coagulopathy and massive collateral circulation resulting from long-term hepatic function lesions and the destructive OLT procedure; (2) bowel congestion and edema from clipping of the portal vein at the anhepatic phase; (3) aggravation of bowel edema from massive fluid resuscitation at the anhepatic and new liver phase [4,12]; (4) accumulation of massive ascitic fluid due to refractory hypoalbuminemia at the early period of OLT [13]. Unlike ascites accumulating slowly before surgery, there is not enough time for any compensatory mechanism to take effect. IAP increases dramatically and steeply in some patients [4,5]. Our data showed that preoperative IAP of all patients did not exceed $6 \mathrm{mmHg}$, but the incidence of postoperative IAH reaching $38.7 \%$, and $79.2 \%$ occurred on the first postoperative day, and usually lasted until the third day after OLT.

The urinary bladder is an extraperitoneal and intraabdomianal organ with a very compliant wall. The pressure in the urinary bladder closely approximates IAP and it is thus very useful in indirectly reflecting any changes in intraperitoneal pressure [9]. The estimation of IAP via bladder pressure measurement is also a noninvasive and highly reproducible method $[9,14]$. Therefore, the urinary bladder technique was employed to measure IAP in our research. However, there is still no agreement in setting the standards for IAH according to IAP levels. Malbrain suggested that IAH should be diagnosed only when IAP exceeded $12 \mathrm{mmHg}$ [15]. We therefore decided to use $20 \mathrm{mmHg}$ as the threshold to highlight the possible deleterious effects of IAH, coinciding with suggestions of most specialists [16,17].

The etiology of ARF after OLT is multifactorial. Among these factors, hypovolemia and massive blood loss at the intraoperative and/or postoperative phase can cause a decrease in renal perfusion, which in turn may be the major trigger for evoking ARF [18]. However, we found no significant differences in the hemodynamic variables (CVP, PAP, MAP) in the first three days after OLT, compared with that before OLT was done, despite of a significant increase in HRs at 24-72 $\mathrm{h}$ postoperatively. This suggests that ARF was not caused by postoperative hypovolemia in our population. In 1876, Wendt reported that IAH could reduce urinary flow [19]. But, only in the last few years has the importance of IAH been recognized by its association with renal impairment $[6,16]$. Recently, a few studies have shown the adverse physiological effects of IAH on ARF after OLT $[4,5]$. To our knowledge, the independent effects of IAH on ARF have not been previously investigated in subjects undergoing OLT.

In the present study, 11 (45.8\%) patients in group IAH developed ARF, and four of them demonstrated oliguria or anuria, compared with three (7.9\%) ARF cases in group NO-IAH. Continuous renal replacement therapy was required in three of those in group IAH but none in group NO-IAH. Statistical differences were noted in blood $\mathrm{Cr}$ levels, BUN levels and urine volume per hour between group IAH and group NO-IAH postoperatively at 24-48 h and at 48-72 h. These results reveal that renal function is quickly and continuously impaired by IAH. Sugrue suggested that the mean time of IAH onset and renal impairment after general abdominal surgery is $1.7 \pm 1.4$ days [6]. In our study, we obtained similar results.

Ulyatt suggested that GFG was a key to renal impairment in patients with IAH [10]. GFG is a mechanical force across the glomerulus and it is equal to the difference between the glomerular filtration pressure and the proximal tubular pressure. In some circumstances, especially when IAP is elevated, proximal tubular pressure can be equated with IAP, and glomerular filtration pressure is estimated as the difference between MAP and IAP. GFG can, therefore, be calculated by the following formula: GFG $=$ MAP- $(2 \times$ IAP $)$. Thus, changes in IAP will have a much greater effect on urine formation than that from a corresponding alteration in MAP. In our sample, we found that group IAH had significantly lower GFG than group NO-IAH during the first $0-72 \mathrm{~h}$ postoperatively. These outcomes suggest that GFG is a special and early parameter for renal impairment in patients with IAH.

Multivariate correlation analysis on perioperative risk factors for ARF showed that ARF was significantly correlated with such factors like age more than 60 years, intraoperative blood transfusion volume over $15 \mathrm{U}$, intraoperative MAP, postoperative IAH, sepsis and respiratory failure. Logistic regression analysis revealed that ARF was significantly and independently associated with postoperative IAH, 
intraoperative MAP and intraoperative blood transfusion volume over $15 \mathrm{U}$. Multivariate forward stepwise model revealed identical results.

A decrease in cardiac output is observed after an increase in afterload, which in turn can be due to mechanical compression of the abdominal vascular beds. On the other hand, a decrease in preload may occur due to direct compression of the inferior vena cava $[12,20,21]$. Increased IAP causes elevation of the diaphragm, which causes an increase in pleural and hence intrathoracic pressure [20,21]. A decrease in preload is exacerbated by this increase in intrathoracic pressure, not only hindering venous return but also causing cardiac compression leading to a decrease in ventricular end-diastolic volume [20]. As a result, these will cause a reduced stroke volume, hypovolemia and a subsequent decrease in renal perfusion and glomerular filtration rate [12,21]. However, in our study, the reversal of hemodynamic disturbance by volume expansion therapy did not ameliorate renal function, indicating that a decrease in cardiac output cannot completely explain the manifestations of renal function deterioration in IAH. There are some other possible mechanisms causing the decrease in glomerular filtration rate, such as direct compression of the renal vessels or renal parenchyma with diminished renal blood flow, or an increase in renal vascular resistance and the redistribution of blood from the renal cortex to the medulla $[4,5,22,23]$. Increases in both plasma renin levels and aldosterone levels have been reported in animals with increased IAP. Plasma renin activity and aldosterone levels were both reported to be significantly decreased by decompression of the abdomen [24]. Recently, Edil reported that IAH caused changes in gene up- and down-regulation in the kidney [25]. Further investigation on renal gene expression may provide insight into the molecular pathophysiology of ARF caused by IAH.

A correlation between elevated IAP and impairment of hepatic perfusion and high hospital mortality rates has been found in various studies [26-29]. However, there were no significant differences in graft function and mortality between group IAH and group NO-IAH. This may be because of the small sample in our study.

In conclusion, this study demonstrates that IAH is an independent risk factor causing ARF during the early postoperative period after OLT. A routine measurement of IAP, such as at every eight hours postoperatively, should be considered. Perhaps IAP should be measured at the end of abdominal closure. It may be helpful to adopt corresponding interventions to ameliorate or prevent renal impairment by IAH at an early period after OLT.

\section{References}

1. Gonwa T A, Klintmalm G B, Levy M, Jennings L S, Goldstein R M, Husberg B S. Impact of pretransplant renal function on survival after liver transplantation. Transplantation, 1995, 59(3): 361-365
2. Gainza F J, Valdivieso A, Quintanilla N, Errazti G, Gastaca M, Campo M, Lampreabe I, Ortiz-de-Urbina J. Evaluation of acute renal failure in the liver transplantation perioperative period: incidence and impact. Transpl Int, 2002, 34(1): 250-251

3. Nair S, Verma S, Thuluvath P J. Pretransplant renal function predicts survival in patients undergoing orthotopic liver transplantation. Hepatology, 2002, 35(5): 1179-1185

4. Biancofiore G, Bindi L, Romanelli A M, Bisa M, Boldrini A, Consani G, Danella A, Urbani L, Filipponi F, Mosca F. Renal failure and abdominal hypertension after liver transplantation: determination of critical intra-abdominal pressure. Liver Transplant, 2002, 8(12): 1175-1181

5. Biancofiore G, Bindi L, Romanelli A M, Bisa M, Boldrini A, Consani G, Danella A, Urbani L, Filipponi F, Mosca F. Postoperative intra-abdominal pressure and renal function after liver transplantation. Arch Surg, 2003, 138(7): 703-706

6. Sugrue M, Jones F, Deane S A, Bishop G, Bauman A, Hillman K. Intra-abdominal hypertension is an independent cause of postoperative renal impairment. Arch Surg, 1999, 134(10): 1082-1085

7. American College of Chest Physicians/Society of Critical Care Medicine Consensus Conference. Definitions for sepsis and organ failure and guidelines for the use of innovative therapies in sepsis. Crit Care Med, 1992, 20(6): 864-874

8. Mcdonald M, Perkins J D, Ralph D, Carithers R L. Postoperative care: immediate. In: Maddery W C, Sorrel M F, eds. Transplantation of The Liver, 2nd ed. Norwalk, NY: Appleton \& Lange, 1996: 171

9. Kron I L, Harman P K, Nolan S P. The measurement on intraabdominal pressure as a criterion for abdominal re-exploration. Ann Surg, 1984, 199(1): 28-30

10. Ulyatt D. Elevated intra-abdominal pressure. Australas Anesth, 1992, 10(3): 108-114

11. Nanasshima A, Pilly P, Verran D J, Painter D, Nakasuji M, Crawford M, Shi L. Analysis of inital poor graft function after orthotopic liver transplantation: experience of an Australian single liver transplantation center. Transplant Proc, 2002, 34(4): 12311235

12. Saggi B H, Sugerman H J, Ivatury R R, Bloomfield G L. Abdominal compartment syndrome. J Trauma, 1998, 45(3): 597-609

13. Chai C J, Guang X D, Chen G H, Wang W Q, Chen B X, Huan $\mathrm{J} F$. Changes and management of effective blood volume at earlier period of OLT. Chin Anesth J, 2000, 20(6): 376-377

14. Fusco M A, Martin S R, Chang M C. Estimation of intraabdominal pressure by bladder pressure measurement: validity and methodology. J Trauma, 2001, 50(2): 297-302

15. Malbrain M L, Chiumello D, Pelosi P, Wilmer A, Brienza N, Malcangi V, Bihari D, Innes R, Cohen J, Singer P, Japiassu A, Kurtop E, de Keulenaer B L, Daelemans R, del Turco M, Cosimini P, Ranieri M, Jacquet L, Laterre P F, Gattinoni L. Prevalence of intra-abdominal hypertension in critically ill patients: a multicentre epidemiological study. Intensive Care Med, 2004, 30(5): 822-829

16. Sugrue M, Buist M D, Hourihan F, Deane S, Bauman A, Hillman K. Prospective study of intra-abdominal hypertension and renal function after laparotomy. Br J Surg, 1995, 82(2): 235-238

17. Raeburn C D, Moore E E, Biffl W L, Johnson J L, Meldrum D R, Offer P J, Franciose R J, Burch J M. The abdominal compartment syndrome is a morbid complication of postinjury damage control surgery. Am J Surg, 2001, 182(6): 542-546

18. Lima E Q, Zanetta D M, Castro I, Massarollo P C, Mies S, Machado M M, Yu L. Risk factors for development of acute renal failure after liver transplantation. Renal Failure, 2003, 25(4): 553-560

19. Wendt E. Uber den einfluss des intraabdominalen Druckes auf die Absonderungsge-schwindigkeit des Harnes. Arch Physiologische Heilkunde, 1876, 57: 527-534 
20. Ridings P C, Bloomfield G L, Blocher C R, Sugerman H J. Cardiopulmonary effects of raised intra-abdominal pressure before and after intravascular volume expansion. J Trauma, 1995, 39(6): 1071-1075

21. Schachtrupp A, Graf J, Tons C, Hoer J, Fackeldey V. Intravascular volume depletion in a 24-hour porcine model of Intraabdominal Hypertension. J Trauma, 2003, 55(4): 734-740

22. Harman P K, Kron I L, McLachlan H D, Freedlender A E. Elevated intra-abdominal pressure and renal function. Ann Surg, 1982, 196(5): 594-597

23. Kirsch A J, Hensle T W, Chang D T, Kayton M L, Olsson C A, Sawczuk I S. Renal effects of $\mathrm{CO}_{2}$ insufflation: oliguria and acute renal dysfunction in a rat pneumoperitoneum model. Urology, 1994, 43(4): 453-459

24. Bloomfield G L, Blocher C R, Fakhry I F, Sica D A, Sugerman $\mathrm{H}$ J. Elevated intra-abdominal pressure increases plasma renin activity and aldosterone levels. J Trauma, 1997, 42(6): 997-1004
25. Edil B H, Tuggle D W, Puffinbarger N K, Mantor P C, Palmer B W, Knutson Z A. The impact of intra-abdominal hypertension on gene expression in the kidney. J Trauma, 2003, 55(5): 857-859

26. Nakatani T, Sakamoto Y, Kaneko I, Ando H, Kobayshi K. Effects of intra-abdominal hypertension on hepatic energy metabolism in a rabbit model. J Trauma, 1998, 44(3): 446-453

27. Yokoyama Y, Alterman D M, Sarmadi A H, Baveja R, Zhang J X, Huynh T, Clemens M G. Hepatic vascular response to elevated intraperitoneal pressure in the Rat. Journal of Surgical Research, 2002, 105(2): 86-94

28. Meldrum D R, Moore F A, Moore E E, Franciose R J, Sauaia A, Burch J M. Prospective characterizationand selective management of the abdominal compartment syndrome. Am J Surg, 1997, 174(6): 667-672

29. Malbrain M. Abdominal pressure in the critically ill: measurement and clinical relevance. Intensive Care Med, 1999, 25(12): 14531458 